\title{
Teacher Candidates' Perceptions of an International Practicum Experience in Italian Schools: Benefits of a Short-Term Placement with Faculty Support
}

\author{
Maria Cantalini-Williams (Nipissing University) \\ Mary Lynn Tessaro (Nipissing University)
}

\begin{abstract}
This study examines the perceptions of teacher candidates (student teachers) participating in a faculty-supervised, international teaching placement in Italian schools. Survey responses and journal reflections, supported by faculty field notes indicate that the benefits could be categorized in four main areas such as: the development of resourcefulness and resilience; increased familiarity with the conditions of international teaching employment; a greater awareness of cultural literacy and comparative education; and an enhancement of language sensitivities and strategies for communicating and teaching. Recommendations suggest that professional growth of the teacher candidates is dependent on sufficient preparation, faculty support and immersion in the experience.
\end{abstract}

\begin{abstract}
Résumé
Cette étude examine les perceptions des futurs enseignants (étudiants en enseignement) participant à un stage international d'enseignement dans des écoles italiennes, supervisé par la faculté. Les résultats d'enquêtes et réflexions de journal, appuyés par des notes de terrain des professeurs, indiquent que les avantages pourraient être classées dans quatre principaux domaines tels que : développement de débrouillardise et de résilience ; familiarité accrue avec les conditions d'emploi pour enseigner à l'étranger ; une plus grande sensibilisation à la littérarité cultuelle et à l'éducation comparative ; et une amélioration des sensibilités linguistiques et stratégies de communication et d'enseignement. Des recommandations suggèrent que le développement professionnel des futurs enseignants dépend d'une préparation adéquate, de support du corps professoral et d'une immersion dans l'expérience.
\end{abstract}

I now feel extremely comfortable with the idea of teaching internationally. Although I know it would be difficult, I feel it would be a challenging, and rewarding opportunity.

(Teacher candidate survey comment, 2008)

In the current context, graduates of teacher education programs in some regions of Canada have difficulty securing full-time employment within school boards, and many need to assume a variety of positions including occasional and international teaching assignments at the beginning of their careers (Transition to Teaching Report, OCT, 2009). While there has been a significant body of research documenting the goals and benefits of international teaching placements (Quezada, 2004, Crossley and Watson, 2006), there is little research on the possibility that the experience also gives candidates the opportunity to consider employment options in an international context. In reality, participation in a supervised short-term 
practicum allows teacher candidates to develop, with support, some understanding of the expected conditions one might encounter while teaching full-time in an international setting.

In this study of a faculty-supervised, international teaching placement in Italy, teacher candidates reported that there were significant benefits to participation in the program, such as the development of resourcefulness and resilience, an awareness of language challenges while teaching English, and an understanding of comparative education practices. Overall, the experience provided opportunities for personal and professional growth for the teacher candidates and an increased familiarity with international employment settings.

\section{INTERNATIONAL TEACHING EXPERIENCES}

The need for the inclusion of international placements did not greatly influence pre-service teacher education until the 1980s (McKay \& Montgomery, 1995). Since then, it appears there has been acknowledgement that the experience of teaching abroad provides a multitude of opportunities for teacher candidates in education programs. However, Kelly (2004) states that there is limited response to the call for international education, and Kissock and Richardson (2010) describe it as "the least well-developed study-abroad programme in terms of numbers undertaking it" (95). Existing models provide future teachers with experiences differing in length, depth, and breadth. Quezada (2004) describes three different types of practicum trips abroad: the tourist approach, the internationalization of the curriculum approach, and a third approach which involves the total immersion of future teachers in the country, school and community.

The literature supports the concept of conducting international practicum placements for a range of benefits. Quezada and Alfaro (2007) categorize these diverse benefits as instructional pedagogy, self-learning, and genuine multiculturalism, all based on various relevant studies (Bryan \& Sprague, 1997; Clement \& Otlaw, 2002; Mahon \& Cushner, 2002; Stachowski \& Visconti, 1997; Stachowski \& Chleb, 1998; and Stachowski, Richardson, \& Henderson, 2003). Broad benefits include increased effectiveness in curriculum implementation, understanding of the world, mutual influence of nation upon nation, cultural understanding of teacher candidates, and personal growth of teacher candidates (Stachowski \& Sparks, 2007). International placements may also lead to opportunities related to employment. (Bryan \& Sprague, 1997; Cushner, 2007; Kissock \& Richardson, 2010).

Under the umbrella term of 'instructional pedagogy', international placements assist teacher candidates in the development of the skills needed to 
teach immigrant children (Blair, 2002). International placements remove blinders on beginning educators, helping them to become reflective practitioners (Kissock \& Richardson, 2010). These placements also have a significant impact on the preconceptions of teacher candidates and how they might judge students (Willard-Holt, 2001), the stereotypes they might hold (Dantas, 2007), and the way that they understand the field of education (Alfaro \& Quezada, 2010). Teacher candidates are likely to experience increased self-efficacy (Stachowski \& Sparks, 2007), increased flexibility and resourcefulness (Bryan \& Sprague, 1997), and an increased ability to critically engage with the "other" with a strengthened global perspective (Dantas, 2007). The new instructional pedagogy brought back to home communities in the teacher candidate's country has an additional effect on his or her immediate educational environment, with the new understandings influencing the teacher candidate's colleagues (Willard-Holt, 2001).

In terms of self-learning, Alfaro and Quezada (2010) state that international placements promote self-reflection in both professional and personal settings. Personal empowerment gained through facing anxieties throughout the planning of and duration of the trip (Mahon \& Cushner, 2002) and through an increased awareness of the self (Stachowski \& Sparks, 2007) also benefit teacher candidates. Cushner (2007) notes that teacher candidates experience these different forms of personal benefits both when entering and exiting the country.

Genuine multiculturalism takes the form of sensitivity to global issues (Kitsantas, 2004), an understanding of diversity (Cushner, 2007), and a renewed global perspective in the classroom (Alfaro \& Quezada, 2010). Crossley and Watson (2006), contend that international education allows teacher candidates to better understand one's own educational system, develop a deeper comprehension of the connections between education and the wider society, consider solutions to identified problems in educational policy and practice, and cultivate an increased sensitivity to different worldviews and cultures. Stachowski and Sparks' (2007) emphasis on the way that international placements help to expand teacher candidates' worldview complements WillardHolt's (2001) explanation of related benefits including developing the knowledge, skills, and attitudes to participate in a pluralistic, interconnected world, perceiving and valuing cultural diversity, having a realistic view of the world, and having the ability to instill this attitude in the minds of their students. Kissock and Richardson (2010) summarize the value of the genuine multiculturalism gained from international placement opportunities as a way to 
help teachers to be able "to teach any child from, or living in, any part of the world" (page 89).

In Bryan and Sprague's (1997) study, it was found that experience from an international placement increased the likelihood that teacher candidates would get hired in the education field because of the way that employers value the life experiences they gain from the placement. This life experience combined with an enhanced understanding of the self makes teacher candidates even more hirable (Kissock \& Richardson, 2010). Cushner (2007) lists other job possibilities taken on by teacher candidates who had participated in an international placement which include foreign student advisors, international program coordinators, international business people, or Foreign Service officers.

\section{THEORETICAL FRAMEWORK AND STUDY RATIONALE}

The theoretical framework for this study was based on the understanding that international teaching placements are of value and offer a range of benefits for participating teacher candidates (Bryan \& Sprague, 1997; Clement \& Otlaw, 2002; Mahon \& Cushner, 2002; Quezada and Alfaro, 2007; Stachowski \& Visconti, 1997; Stachowski \& Chleb, 1998; and Stachowski, Richardson, \& Henderson, 2003). However, in an effort to continue to search for ways to ensure the placements are optimally beneficial for teacher candidates, there are organizational considerations which should be taken into account including the nature of orientation sessions, the choice of accommodations, the amount of communications with faculty supervisors and the variety of activities conducted in the host placement (Quezada, 2004). In developing this study, the authors hoped to build on Quezada's (2004) work by considering the recommendations for the inclusion of a planning phase, an actual service component with opportunities for reflection, financial support for the teacher candidates, and follow-up activities. In addition, the findings of Quezada and Alfaro (2007) formed the foundation of the research question seeking to determine the potential benefits of an international practicum placement.

This study investigated the perceptions of teacher candidates after participation in a three week practicum placement teaching English in Italian schools, with the supervision and support of faculty advisors. Little or no research has been conducted to examine the effects of such an experience in the country of Italy which is familiar to most Canadians through media representations. In the review of related research, it did not appear that previous studies had examined practicum settings with conditions such as those incorporated in this study including close faculty supervision and professional 
development opportunities in conjunction with the partner university and host faculty of education.

The guiding research questions for this study were:

1. How was the preparation for the international practicum experience helpful for participants? How could preparation be improved?

2. What were the major benefits and new understandings identified by participants as a result of the international practicum experience?

The research questions were intended to provide feedback from the participants about their international practicum experience in Italy and potential effects on their personal and professional growth.

\section{STUDY CONTEXT}

The participants of this study were teacher candidates in a four-year concurrent teacher education program offered at a small regional campus of a mid-size Ontario Faculty of Education. The regional campus had a student population of approximately 700 teacher candidates in years one to four, with approximately 140 candidates in year four of the program. This teacher education program was developed to mirror the consecutive program of the main campus with the inclusion of an optional international placement in the fourth and final year of the program based upon perceptions that an international placement would enhance candidates' abilities to develop effective teaching skills and global awareness.

The traditional practicum program component for the concurrent education program consisted of a field placement in the same classroom each Monday (excluding exam periods) from October through March, for 15 single days followed by one full week in April, for a total of 20 practicum days per annum. This practicum structure was in place for years one, two, and three of the program, with fourth year candidates taking part in three block placements, each lasting three consecutive weeks. The international practicum to Italy was the last of the block placements in year four of the concurrent education program. The teacher candidates had to apply to participate in this experience and assumed full costs of the trip. They were accompanied by two faculty members who were considered trip leaders and supervisors of the practicum. The practicum experience was organized by these faculty leaders in coordination with the International Office of the university.

The international practicum experience was planned as an official partnership between the host faculty of education in an Italian university in central Italy and the home university in Ontario with ongoing contacts made between officials from both universities. A formal agreement was signed and it was understood that annually a group of approximately 20-25 teacher candidates 
and two professors from the concurrent education program would travel to Italy in order to teach English to students in Italian schools, in collaboration with the teachers of English in the selected schools.

The practice teaching context in the Italian schools consisted of groups of teacher candidates (on average three to four) placed with an Italian associate (host) teacher of English. The associate teachers each spoke English quite fluently and were prepared to allow the teacher candidates to initially observe and subsequently teach lessons to their students of varying grades within two elementary schools. The schools used in this international experience were in the central core of the city and the students were from diverse cultural backgrounds. The grades ranged from grades one to eight. The teacher candidates came prepared to teach lessons about such topics as Canadian seasons, sports, animals, and other areas of interest. The associate teachers had some requests that the teacher candidates teach lessons related to their English curriculum including safety, feelings and the function of human body organs and systems.

The teacher candidates taught about ten days in the time period that they were in schools, due to state holidays and other interruptions, but were immersed in the Italian culture throughout their three week stay in Italy. Another facet of the international experience was the opportunity to share information about each others' educational systems. The Canadian teacher candidates and faculty leaders made presentations on our school system and teacher training program to the Italian educators, faculty advisors and teacher candidates. The faculty members of the Italian university and schools reciprocated with explanations of their education system and university programs for teacher education. Teacher candidates of both universities had sharing sessions each year to compare features of their respective programs.

\section{METHODOLOGY}

This study consisted of the collection of teacher candidates' perceptions after a three week international practicum placement in schools of central Italy. It includes the data compiled over a three-year period of annual trips. The perceptions of participants were gathered from surveys completed by the teacher candidates and supported by information from their journals and the field notes of faculty leaders.

Each year, the participating teacher candidates were asked to keep a reflective journal to note their observations of the school system in Italy, observing in particular one 'research' area of interest. This research question was to pertain to an area that the teacher candidate found of particular interest and worthy of further observations. The faculty leaders also recorded their 
observations of the teacher candidates' actions and comments, along with observations of the Italian educational system. The major method of collecting the perceptions of the teacher candidates was their completion of a survey which included 18 open-ended questions on a variety of topics such as means of preparation for the trip, benefits and challenges, observations of the Italian school system, and personal effects of the experience. The survey was completed in a confidential manner after the trip by each participant and was submitted to a research assistant electronically (within three months) in order that the trip leaders did not have access to the participant's name of each completed survey. The faculty leaders were with the students each day of the trip and recorded many observations. The main faculty leader of each trip was consistent throughout the three years of placements, but the accompanying faculty leader was different for two of the trips. The faculty leaders were also responsible for completing a teaching evaluation form for each teacher candidate based on observations of a taught English lesson. Information gathered for these evaluations provided an example of field notes that were also used in the analysis.

\section{FINDINGS}

Of the 63 participants in the international practicum placements in Italy, about half of the participants responded with completed surveys within a year of each practicum. The research assistant received and forwarded 31 completed surveys. The responses to the questions on the survey were analyzed through coding and categorizing of key idea units as described by Creswell (2002). The idea units were collapsed into categorical clusters and themes representing the main perceptions of the participants. The research assistant independently reviewed the data, and provided a summary of the major findings prior to the review of the data by the two faculty leaders (researchers) of this study. The faculty leaders then met to review the summary provided by the research assistant and used field notes from observations to further develop the themes and patterns that emerged from the survey responses. No major differences were noted between the perceptions of participants in each year of the experience and the surveys were not analyzed until after the third set of surveys were received.

Following this process of data analysis, four broad themes were identified:

- Language Challenges and Barriers: A new understanding of the challenges related to teaching non-English speaking students and communicating in an unfamiliar language 
- Awareness of Cultural Literacy and Comparative Education: The development of cultural awareness and comparisons between different educational systems

- Resourcefulness and Resilience: The appreciation of the need for preparation, flexibility, adaptability and open-mindedness when teaching and travelling in a new society with diverse expectations

- Employment Interest in International Opportunities: The articulation of a better understanding regarding international teaching employment opportunities

Each of these four themes is described more fully with accompanying quotes from participating teacher candidates. Within each of these themes, the teacher candidates reported on the positive features and results of the international practicum experience. They also indicated features of the preparation that might have been improved upon for a smoother transition into Italian schools.

\section{LANGUAGE CHALLENGES AND BARRIERS: A NEW UNDERSTANDING OF THE CHALLENGES RELATED TO COMMUNICATING IN AN UNFAMILIAR LANGUAGE AND TEACHING NON-ENGLISH SPEAKING STUDENTS}

All participants reported that they struggled with the language barrier, and felt uncomfortable learning a new language while simultaneously trying to understand important terms in order to communicate in the Italian environment. The teacher candidates reported that this state of discomfort was an effective learning tool for understanding the feelings of English language learners in their future classrooms. Some respondents expressed that it was the language barrier that made the experience unique and that it provided them with an opportunity to learn strategies for overcoming the barrier. In addition to the challenges in communicating in the environment, the language barrier was challenging for teaching the Italian students. The participants noted that they learned many techniques for teaching English to the Italian students such as using props, hand and facial gestures, songs and repetition. Many respondents indicated that they appreciated the pre-trip sessions provided on teaching English as a Second Language (ESL), but that they would have benefitted from increased knowledge and skills in ESL along with lessons or a course in the Italian language.

One of the greatest benefits I feel was being able to be the teacher, yet having no way of communicating with the students and having to find a way to teach students English. It was as if I was the ESL student in the class, trying to communicate to the students.

It gave me an understanding of what it must be like to be an ESL student. 
A drawback was the language barrier. I was under the impression that the associate teachers and the students would know more English.

Throughout the placement I came to fully realize that patience is definitely something you need to have a lot of when it comes to teaching English to non-English speaking individuals. Over the course of the teaching block I came to learn that speaking slowly, using hand gestures, using pictures and having multiple ways of describing a specific thing at hand are all crucial elements to teaching another language with a greater chance of success.

\section{AWARENESS OF CULTURAL LITERACY AND COMPARATIVE EDUCATION: THE DEVELOPMENT OF CULTURAL AWARENESS AND COMPARISONS BETWEEN DIFFERENT EDUCATIONAL SYSTEMS}

Reflections of teacher candidates strongly indicated an increase in awareness of the Italian culture and school system. Even though the Italian culture is prominent in the media, the participants reported that they learned authentic information about the Italian culture through their immersion in society and the schools. The comments made by teacher candidates showed an appreciation of the 'behind the scenes' information gathered through interactions with the associate teachers and the students. Through invitations to eat meals at the homes of teachers and through daily contacts with school children, the teacher candidates were able to note how the Italian cultural values affect the school system beliefs and practices. For example, the eating of large meals at lunch was directly related to the structure of the school day. In the short day structure, students went home to eat a large lunch and in the extended day, students have a long lunch break of one hour in order to eat a hot, catered lunch, unlike our school system where students eat bagged lunches in 20 minute periods. Many similar examples of comparisons were made such as the lack of clocks in classrooms, the absence of classroom management techniques, the preponderance of parents in the schools, the focus on the Arts and the open displays of affection among teachers and students. Cultural literacy was developed in the participants in that they became more familiar and comfortable with a diverse set of values and norms than they had experienced in their past.

It was a once in a lifetime experience getting to see what life is like in another culture and getting to see how the school system was similar and different to what we are entering as teachers. 
In Italian school systems, there seems to be little evidence of planning and classroom management strategies were ineffective. Students are rigorously tested in their school system.

Students in Italian schools were very affectionate with their teachers...lots of hugs.

Some of the benefits were seeing the different aspects and viewpoints of another culture's education system. Being exposed to these differences has expanded my own understanding of the world that we live in. Experiencing the Italian culture will also make me a more well-rounded, tolerant and worldly individual, both in everyday life and in the classroom.

There were indeed many differences between the two systems; however' in my opinion the most prominent was the emphasis placed on the Arts, which can be noted throughout the Italian system. Furthermore the elongated lunch breaks are found only within the Italian school system. In addition there are no set recess times and the schedule of the day is dependent on that day's activities, the weather outside and inclinations of the various teachers.

Classroom management was not nearly as emphasized in Italy as it is in Canada. Students are not expected to act as "robots" and rather are free to make many personal choices and decisions based on their interests. This laissez-faire attitude was definitely not always an advantage as the school did become chaotic at times. Even using few classroom management techniques the teachers did still possess control over the class and are truly adored by their students.

My main focus of observation in the Italian schools related to student engagement. I found that most students exhibited very high engagement in their classroom, and a genuine interest in the topic at hand. They also seemed less stressed than Canadian students of the same age, and while it was a difficult area to observe (as I understand little Italian), they were genuinely happy and enthusiastic about their time in school. The students engage in a far more hands-on culture than we would encourage, but I saw very little malicious bullying or incidents of that nature. I think student engagement, in my own teaching, rose when the students were given group activities or differentiated instruction, and I think this would be an interesting angle for the Italian school system to explore.

\section{RESOURCEFULNESS AND RESILIENCE: THE APPRECIATION OF THE NEED FOR PREPARATION, FLEXIBILITY, ADAPTABILITY AND}




\section{OPEN-MINDEDNESS WHEN TEACHING AND TRAVELLING IN A NEW SOCIETY WITH DIVERSE EXPECTATIONS}

The majority of the respondents were positive about the international experience, especially the value of developing resourcefulness, cooperative skills and flexibility in a new environment. They indicated that the preparations for the trip such as planned units and research on Italian geography were useful, but there were still unexpected incidents and novel situations that required a need to step outside of their 'comfort zones'. Respondents over the years remarked that learning some Italian terms and strategies for teaching English language learners were essential since they had to quickly assimilate new information and make accommodations to their schema of teaching and learning in order to function in the Italian classrooms and society. They needed to rely on limited resources and quickly develop lessons in response to associate teachers' expectations. In addition, the group teaching situation presented challenges in co-planning and co-teaching that had not been experienced in previous practicum placements in Ontario where teacher candidates had traditionally taught independently of each other.

The greatest benefits were the life experiences from travelling, sharing culture, sharing work, and sharing ideas.

Student teachers should not be afraid to step out of their comfort zones and take in new experiences.

I think my new learning in the international experience was rapid but long-lasting. We needed to retain every new word and piece of information, but it was a wonderful experience to stress the importance of flexibility and openness in the classroom. I think that I learned just as much (if not more!) from my students than the information I taught them. Be flexible. Things change last minute and associate teachers have different expectations in each class. Be ready to teach anything to anyone at anytime. Do not stress about how well you are doing if switching your plans is not something that you find easy to do. Most associates are just happy to have a visitor.

\section{EMPLOYMENT INTEREST IN INTERNATIONAL OPPORTUNITIES: THE ARTICULATION OF A BETTER UNDERSTANDING REGARDING INTERNATIONAL TEACHING EMPLOYMENT OPPORTUNITIES}

The participants of this experience overwhelmingly reported an interest in future employment opportunities in teaching abroad but some teacher candidates were reticent and narrowed their interest to English speaking countries or to short-term placements that may be unpaid positions. Most teacher candidates indicated that 
they selected the optional international practicum placement since it provided a 'safe' opportunity to experiment with the concept of international teaching due to fact that the practicum was short-term and facilitated by faculty leaders. The international experience in Italy allowed the participants to be engaged in a teaching situation that was not greatly dissimilar to the Ontario schools and yet provided exposure to different school expectations and structures. The experience of participating in an international practicum confirmed most of the participants' desire to teach abroad and affirmed for them that employment opportunities abroad may be appropriate and aligned to their career plans.

For a minority of teacher candidates, the practicum experience in Italy illustrated that they preferred to teach in English-speaking countries only due to the experience of dissonance when confronted with language barriers. A few teacher candidates indicated that this experience allowed them the opportunity to 'taste' international teaching, but they would not seek long-term employment outside of their home country. They were convinced that teaching in another country and school on a short-term placement was valuable, as well as sufficient for gaining global awareness, and that employment abroad was not suitable for their preferences.

I decided to participate in an international placement so that I would have first-hand experience in education systems other than Ontario. I am considering teaching abroad, and this was an excellent opportunity to try teaching in a different environment.

I feel that I now can picture myself teaching abroad.

This experience has left me wanting more...

I would definitely now want to teach internationally after this experience. In the future I fully anticipate participating in some sort of international employment opportunity. As a result this placement was an excellent opportunity and learning experience.

I am seriously considering an international employment opportunity that has been made available to me, although it is in the United Kingdom so English will be the first language. If I was bilingual in any other country, I would definitely travel to teach English.

I do not want to participate in an international employment opportunity. I think that the teaching placements are a great way to gain experience; however I would rather only visit other countries for a shorter period of time to see their school system and gain an understanding of their curriculum.

In a review of the findings, it is obvious that the four main themes reflected both benefits and drawbacks of the international practicum experience in Italy. The 
supporting quotes of the participants indicate that overall their perceptions of the experience were positive, but that certain variables or conditions could have enriched the experience.

\section{DISCUSSION}

The research literature related to international practicum experiences clearly outlines the benefits to participants and articulates the conditions that affect the perceptions of teacher candidates (Blair, 2002; Kitsantas, 2004). The themes categorized by various studies refer to the benefits as instructional pedagogy, self-learning and genuine multiculturalism (Bryan \& Sprague, 1997; Mahon \& Cushner, 2002; Stachowski, Richardson \& Henderson, 2003). The findings of the present study confirm and extend the results of previous studies in this field. The pivotal study of Quezada (2004) defined the conditions necessary for success of the practicum experience and included preparation, a service component with opportunities to reflect, financial assistance for the participants, and follow-up activities. Most of these conditions were also present in the practicum in Italy and were reported to be important contributors to the positive experience.

The present study identified the main themes and patterns of participants' perceptions of an international experience related to global awareness and language teaching. Additionally, this study expanded on past findings (Cushner, 2007; Kissock and Richardson, 2010) since it was related to Italian school settings and included strong faculty support. Previous studies had not examined international teaching experiences of teacher candidates in Italy nor included the variable of faculty support with diverse professional development opportunities in the practicum. The present study, which analyzed the perceptions of teacher candidates over a three year period, found that a short practicum experience in Italy was very beneficial for the participants, with reported recommendations for further enhancements. The study findings can be described in the four main areas of: Resilience and Resourcefulness, Employment Interest in International Settings, Awareness of Culture and Comparative Education and Language Challenges and Barriers. It is interesting to note that the four main themes could be compacted and synthesized as Resilience, Employment, Awareness and Language creating the acronym REAL. Even though the practicum placement was only three weeks in duration, the participants reported that it was an experience with REAL benefits in that it increased areas such as resilience and resourcefulness, employment opportunities, awareness of cultural/educational differences and language sensitivities and barriers. The present study builds on the research literature related to international experiences since participants articulated their varying interests in employment opportunities in international 
settings. Participants used the international experience to experiment with the concept of teaching abroad.

Within the four main theme areas, the teacher candidates made recommendations for each of the preparation, service learning and reflection stages (Quezada, 2004). They recommended that the preparation phase include more instruction in teaching a second language, greater knowledge of the host school system and some acquisition of key Italian terms. Teacher candidates were also very focused on the benefits of actually teaching in the schools and consistently reported on the desire to be immersed and to teach as much as possible to reap the maximum benefits from the experience. Regarding the reflection stage, the teacher candidates from the present study indicated that they benefitted from the opportunities to develop research questions to guide their reflections and from the professional development activities with the host university, associate teachers and faculty of education students.

It appears that the strong support of faculty and the facilitation of professional development opportunities by faculty with the host university may have positively affected the perceptions and learning of the teacher candidates. Crossley and Watson (2006) found that the experience can be advantageous for both the faculty and the teacher candidates involved in the experience. Related to the role of the faculty leaders, is the finding from Dantas (2007) that accompanying faculty should assist participants in building understanding rather than just act as trip leader and organizer. A future study should perhaps investigate the role of the faculty leader in the practicum experience and determine if this is a variable that has compensated for the short period of the practicum, in that faculty on these trips assisted teacher candidates on a daily basis and supervised the teaching component. Additionally, it would be interesting to determine if the element of faculty supervision is a deciding factor in student participation since our program consistently has approximately $35 \%$ participation rate of our eligible student population in international experiences on a yearly basis to Italy and a similar practicum with faculty support in Kenya. Quezada (2004) had indicated that financial assistance is a variable affecting the perceptions of teacher candidates involved in an international practicum placement. The present study did not examine the impact of a lack of financial supported on the participants, but a future study might examine the effects of substantial fund-raising efforts or financial support on the resulting perceptions of the teacher candidates.

The limitations of the present study are evident to the researchers. The response rate of $50 \%$ may have been improved if the respondents were asked to complete the surveys immediately after the experience rather than electronically 
within a three-month period. Also, to complement the survey responses, it might have been beneficial to conduct focus groups with the participants, to further probe responses. A study on a long-term basis would be interesting to determine the effects of an international practicum on teaching careers several years after graduation.

\section{CONCLUSIONS}

The participants of the teaching practicum in Italy, over a three year period, reported that the experience of teaching English in Italian schools was extremely beneficial to increase their: resourcefulness/resilience; employment opportunities; awareness of various cultures and educational systems; and knowledge of language sensitivities to challenges and barriers of second language learning. Their perceptions can be summarized by the acronym REAL to describe the benefits for the teacher candidates. The present study builds on the findings from previous research in this area. From this study, it is evident that a short term practicum with adequate preparation, strong faculty support and immersion in the host schools, in addition to diverse opportunities to present and reflect on new learning will result in REAL benefits as perceived by participating teacher candidates. Recommendations include sufficient prior learning about the host language and school system, sustained teaching opportunities and the inclusion of professional development activities with peers/colleagues in the host university. Further research in this area could study the long-term effects on educators who had participated in an international practicum experience in Italy. Many former participants have returned to campus to enthusiastically describe how the experience in Italy has touched their lives deeply. It would be very interesting to follow-up with these graduates to determine how the short-term international practicum, with faculty support, might potentially have had a variety of lasting positive impacts on their personal lives and careers.

\section{References}

Alfaro, C. \& Quezada, R. (2010) International teacher professional development: Teacher reflections of authentic teaching and learning experiences. Teaching Education, 21(1), 47-59.

Blair, J. (2002). Colleges sending teacher-candidates to see the world. Education Week, 22(15), 8.

Bryan, S. L., \& Sprague, M. M. (1997). The effect of overseas internships on early teaching experiences. The Clearing House, 70(4), 199-201.

Clement C., M. \& Otlaw, E., M. (2002). Student teaching abroad: Learning about teaching, culture, and self. Kappa Delta Pi Record, 38(4), 180-183.

Creswell, J. W. (2002). Educational research: Planning, conducting, and evaluating quantitative and qualitative research. Upper Saddle River, NJ: Merrill Prentice Hall.

Crossley, M. \& Watson, K. (2006). Comparative and international research in education globalization, context and difference. New York: Routledge Falmer.

Cushner, K. (2007). The role of experience in the making of internationally-minded teachers. Teacher Education Quarterly, 34(1), 27-39.

Dantas, M. (2007). Building teacher competency to work with diverse learners in the context of international 
education. Teacher Education Quarterly, 34(1), 75-94.

Kelly, J. A. (2004). Teaching the world: A new requirement for teacher preparation. Phi Delta Kappan, 86(3), 219-221.

Kissock, C. \& Richardson, P. (2010). Calling for action within the teaching profession: it is time to internationalize teacher education. Teaching Education, 21(1). 89-101.

Kitsantas, A. (2004). Studying abroad: The role of college students' goals on the development of cross cultural skills and global understanding. College Student Journal, 38(3), 441-452.

Mahon, J. \& Cushner, K. (2002). The overseas student teaching experience: Creating optimal cultural learning. Multicultural Perspectives, 4(3), 3-8.

McKay, J. \& Montgomery, J. (1995, April). Changes in perceptions: A comparative study of the experiential learning of international student teachers. Paper presented at the annual meeting of the American Educational Research Association, San Francisco, CA.

Ontario College of Teachers (2009) Transition to Teaching, Retrieved July 15 from http://www.oct.ca/publications/PDF/transitions09_e.pdf

Quezada, R. L. (2004). Beyond educational tourism: Lessons learned while student teaching abroad. International Education Journal, 5(4), 458-465.

Quezada, R. L., \& Alfaro, C. (2007). Biliteracy teachers' self-reflections of their accounts while student teaching abroad: Speaking from "the other side". Teacher Education Quarterly, 34(1), 95-113.

Stachowski, L. \& Chleb, J. (1998). Foreign educators provide feedback for the improvement of international student teaching experiences. Action in Teacher Education, 19(4), 119-130.

Stachowski, L., Richardson, J., \& Henderson, M. (2003). Student teachers report on the influence of cultural values on classroom practice and community involvement: Perspectives from the Navajo reservation and from abroad. The Teacher Educator, 39(1), 52-63.

Stachowski, L. \& Sparks, T. (2007). Thirty years and 2,000 student teachers later: An overseas student teaching project that is popular, successful, and replicable. Teacher Education Quarterly, 34(1), 115-132.

Stachowski, L. \& Visconti, V. (1997). Adaptations for success: U.S. student teachers living and teaching abroad. International Education, 26, 5-20.

Willard-Holt, C. (2001). The impact of a short-term international experience for preservice teachers. Teaching and Teacher Education, 17(4) 505-517.

Mary Lynn Tessaro is an assistant professor at Nipissing University. Her research interests include literacy and fieldwork in teacher education. She can be reached at marylynt@nipissingu.ca.

Maria Cantalini-Williams is an Associate Dean (Interim) at the Brantford campus of Nipissing University. Her research interests focus on early education practices and teacher education programs. She can be contacted at mariac@ nipissingu.ca. 